\title{
Development and Validation of a Spectrofluorimetric Method for the Assay of Tetracycline in Capsules
}

\author{
Lucien Murhula Namegabe ${ }^{{ }^{*}}$, Serigne Omar Sarr2,3, Yérim Mbagnick Diop ${ }^{2,3}$ \\ ${ }^{1}$ Department of Galenic Pharmacy, Official University of Bukavu, Bukavu, Democratic Republic of the Congo \\ ${ }^{2}$ Analytical Chemistry and Food Sciences Laboratory, Cheikh Anta Diop University, Dakar, Senegal \\ ${ }^{3}$ National Medecines Control Laboratory, Dakar, Senegal \\ Email: *murhulan@yahoo.fr
}

How to cite this paper: Namegabe, L.M., Sarr, S.O. and Diop, Y.M. (2018) Development and Validation of a Spectrofluorimetric Method for the Assay of Tetracycline in Capsules. American Journal of Analytical Chemistry, 9, 162-170.

https://doi.org/10.4236/ajac.2018.93014

Received: February 7, 2018

Accepted: March 12, 2018

Published: March 15, 2018

Copyright $\odot 2018$ by authors and Scientific Research Publishing Inc. This work is licensed under the Creative Commons Attribution International License (CC BY 4.0).

http://creativecommons.org/licenses/by/4.0/

\begin{abstract}
The purpose of this study is to develop and validate a method for the analysis of tetracycline capsules by spectrofluorimetry. A pH 9 borate buffer was used as diluent of tetracycline after reaction with magnesium salt at the excitation wavelength of $372 \mathrm{~nm}$ and $516 \mathrm{~nm}$ of emission. A linear response was observed between $0.25 \mu \mathrm{g} / \mathrm{mL}$ and $1.5 \mu \mathrm{g} / \mathrm{mL}$ with a correlation coefficient (R) of 0.9998 . The detection and quantification limits found are $0.0125 \mu \mathrm{g} / \mathrm{mL}$ and $0.0412 \mu \mathrm{g} / \mathrm{mL}$ respectively. The proposed method proved trueness with a recovery between $99.88 \%$ and $101.10 \%$. The relative standard deviations of repeatability and intermediate precision found $\leq 2.88 \%$ reflected a good precision of the method. The proposed method is therefore valid within the limits of $90 \%$ to $110 \%$. The proposed method was applied to the quality control of 9 tetracycline samples from market and gave results in accordance with the pharmacopoeia standards.
\end{abstract}

\section{Keywords}

Validation, Spectrofluorimetry, Tetracycline

\section{Introduction}

Tetracycline hydrochloride (THC) is a broad-spectrum polyketide antibiotic produced by the genus Streptomyces. It exerts a bacteriostatic effect on bacteria by reversibly binding the $30 \mathrm{~S}$ ribosomal subunit of bacteria and blocking the binding of tRNA to the ribosome acceptor site. It also binds to some extent to 
the bacterial 50S ribosomal subunit and can alter the cytoplasmic membrane causing leakage of intracellular components of bacterial cells [1].

A large number of analytical techniques for the determination of tetracycline and its degradation products have been reported, particularly in biological fluids and pharmaceuticals such as spectrophotometry [2] [3] which is of limited utility due to its non-specificity. More efficient separative methods, such as capillary electrophoresis [4] and high performance liquid chromatography [5] [6] using UV and fluorescence detectors require a lot of time, proven expertise and a very high operating cost. This limits their use in routine quality control and especially in developing countries with limited resources. The aim of this study is to validate a spectrofluorometric method for tetracycline assay in capsules by using the accuracy profile approach [7]. This method has proved to be simple, sensitive, fast, efficient and cheap.

\section{Material and Method}

\subsection{Materials}

\subsubsection{Apparatus}

A Perkin Elmer luminescence spectrometer model LS $45^{\circ}$ (Perkin Elmer instruments, Massachusetts, USA) connected to a Fujitsu Siemens computer loaded with the FLwinlab ${ }^{\circledR}$ application software was used.

\subsubsection{Reagent}

The following reagents and chemicals of analytical grade (except specific indication) were used:

Potassium dihydrogenphosphate $\left(\mathrm{KH}_{2} \mathrm{PO}_{4}\right)$, hydrogenphosphatedisodium $\left(\mathrm{Na}_{2} \mathrm{HPO}_{4}\right)$, boric acid, Sodium hydroxide both from sigma-aldrich, Tetracycline hydrochloride (Figure 1) was provided by the European Pharmacopeia.

Purified water was produced in situ with a Milli-Q Ultrapure Water System (Millipore, Molsheim, France).

\subsection{Method}

\subsubsection{Analytical Parameters}

Optimum reaction conditions have been studied such as: The solvent, Effect of magnesium sulphate, Stability of tetracycline in water and Influence of $\mathrm{pH}$.

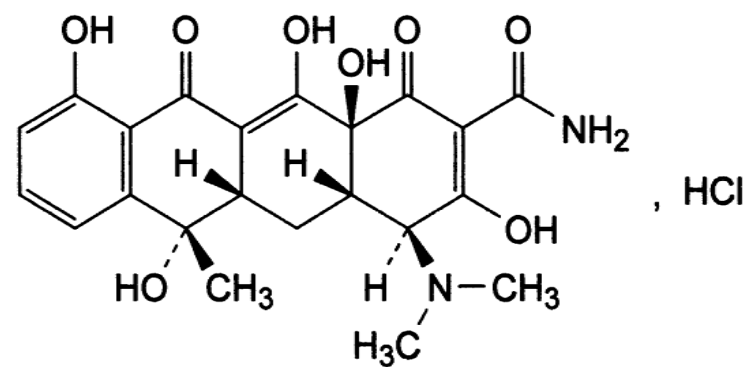

Figure 1. Structure of tetracycline hydrochloride. 


\subsubsection{Preparation of Solutions for the Determination of the Calibration Curve}

$10.00 \mathrm{mg}$ of THC are dissolved in $100 \mathrm{~mL}$ of distilled water to obtain the standard solution (SS). $0.5-1-1.5-2-2.5$ and $3 \mathrm{~mL}$ of the SS are transferred respectively into the $200 \mathrm{~mL}$ volumetric flasks and diluted to the mark. $5 \mathrm{~mL}$ of the $\mathrm{pH} 9$ buffer solution are added to each $5 \mathrm{~mL}$ of dilution followed by $2.5 \mathrm{~mL}$ of the $\mathrm{MgSO}_{4}$ solution $(0.75 \mathrm{M})$.

\subsubsection{Accuracy Profile}

Accuracy is the total error after the sum of systematic error (trueness) and random errors (precision). It is represented by an accuracy profile for the area of measures $(75 \%-125 \%)$. Accuracy of the method is established through the accuracy profile described by Feinberg.

The accuracy profile approach allows to determine simultaneously the recovery and precision of the method using standard and validation solutions as previously described [8].

\section{1) Preparation of Standard Solution}

Three solutions of concentration of $0.75-1-1.25 \mu \mathrm{g} / \mathrm{mL}$ are prepared. $5 \mathrm{ml}$ of each dilution, $5 \mathrm{~mL}$ of the $\mathrm{pH} 9$ buffer solution and $2.5 \mathrm{~mL}$ of the $\mathrm{MgSO}_{4}$ solution $(0.75 \mathrm{M})$ are mixed in a conical tube. The reading of the fluorescence intensity is carried out after $25 \mathrm{~min}$ at $372 \mathrm{~nm}$ of excitation and $516 \mathrm{~nm}$ of emission.

\section{2) Preparation of Test Solution}

The reference sample for validation is reconstituted from the active ingredient (tetracycline) and the matrix (Lactose, Mannitol, magnesium stearate and starch), thus the stock solution is made of $10 \mathrm{mg}$ of tetracycline and $10 \mathrm{mg}$ of the matrix dissolved in $100 \mathrm{~mL}$ of water and filtered. Solutions of concentrations of $0.75-1-1.25 \mu \mathrm{g} / \mathrm{mL}$ are prepared. $5 \mathrm{~mL}$ of the buffer solution at $\mathrm{pH} 9$ and $2.5 \mathrm{~mL}$ of the $\mathrm{MgSO}_{4}$ solution $(0.75 \mathrm{M})$ are added to $5 \mathrm{~mL}$ of each solution. The reading of the fluorescence intensity is carried out after $25 \mathrm{~min}$ at $372 \mathrm{~nm}$ of excitation and $516 \mathrm{~nm}$ of emission.

\subsubsection{Limit of Detection (LOD) and Limit of Quantification (LOQ)}

The limit of detection is estimated by diluting a solution of known concentration until the lowest near detectable signal is different from that of blank, while the limit of quantification is 3.3 times the limit of detection [9]. They were determined as specified in the ICH (International Conference on Harmonisation) protocol [10].

\subsubsection{Application of the Method}

A test sample of $10 \mathrm{mg}$ of tetracycline is carried out on the powder emptied from 5 capsules (taking into account the average weight). After dissolution in $100 \mathrm{~mL}$ of distilled water, homogenization with ultrasound for 10 minutes and filtration, $2 \mathrm{~mL}$ of the filtrate are diluted to $200 \mathrm{~mL}$ to obtain a solution of $1 \mu \mathrm{g} / \mathrm{mL}$ of THC. To $5 \mathrm{~mL}$ of the $1 \mu \mathrm{g} / \mathrm{mL}$ solution are added $5 \mathrm{~mL}$ of Borate buffer at $\mathrm{pH} 9$ and $2.5 \mathrm{ml}$ of the $0.75 \mathrm{M} \mathrm{MgSO}_{4}$ solution. The reading of the fluorescence inten- 
sity is carried out after $25 \mathrm{~min}$ at $372 \mathrm{~nm}$ of excitation and $516 \mathrm{~nm}$ of emission.

\section{Results}

\subsection{Study of the Optimal Reaction Conditions}

\subsubsection{Effect of Solvent on Fluorescence Intensity}

A solution with a cloudy appearance is obtained when the magnesium sulfate is put into the THC solution in basic medium. This solution is unusable due to the formation of insoluble compounds. On the other hand, in the water a weak signal is observed as it appears in Table 1.

\subsubsection{Influence of $\mathrm{pH}$}

Signals are stronger with basic buffers than acidic buffers (Figure 2). An excellent and stable signal is observed at $\mathrm{pH}$ 9. The use of $\mathrm{MgSO}_{4}$ at $\mathrm{pH} 5.6$ helped to boost the fluorescence of tetracycline dissolved in water (non fluorescent). The complex formed between THC and Mg gave a good stability in function of time.

\subsection{Study of Selectivity}

The comparison of data found during the analysis of THC pure product and when it is with the other substances which accompany it in galenic presentation (the excipients) gave two spectra (Figure 3 and Figure 4).

\subsection{Graph Calibration}

Employing the conditions described in the procedure, a calibration curve was drawn in Figure 5.

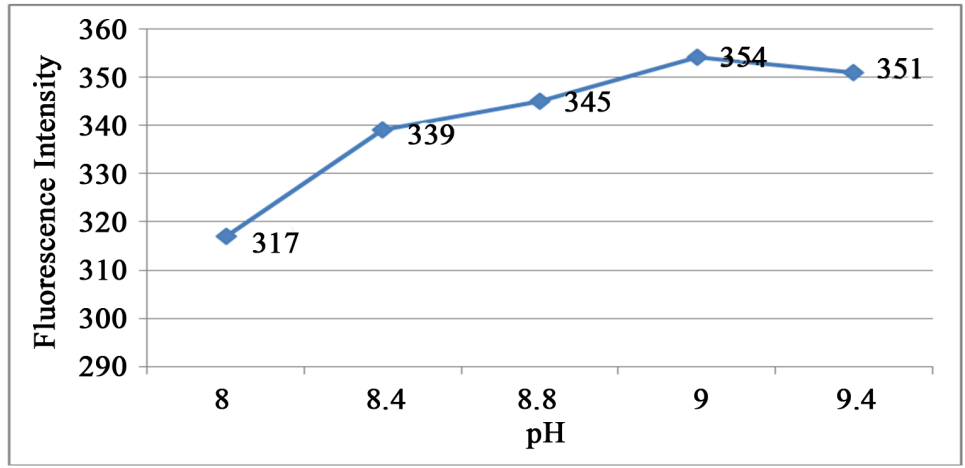

Figure 2. Effect of $\mathrm{pH}$ on the fluorescence intensity.

Table 1. Effect of magnesium sulfate on the bypass.

\begin{tabular}{ccc}
\hline Settings & $\mathrm{NaOH} 0.5 \mu \mathrm{g} / \mathrm{mL}$ & $\mathrm{H}_{2} \mathrm{O} 5 \mu \mathrm{g} / \mathrm{mL}$ \\
\hline & $\mathrm{MgSO}_{4}$ & $\mathrm{MgSO}_{4}$ à pH 5.6 \\
$\mathrm{ex}$ & ------ & $380 \mathrm{~nm}$ \\
$\mathrm{em}$ & ----- & $520 \mathrm{~nm}$ \\
$\mathrm{FI}^{*}$ & ----- & 103 \\
Observation & Non exploitable & stable \\
\hline
\end{tabular}




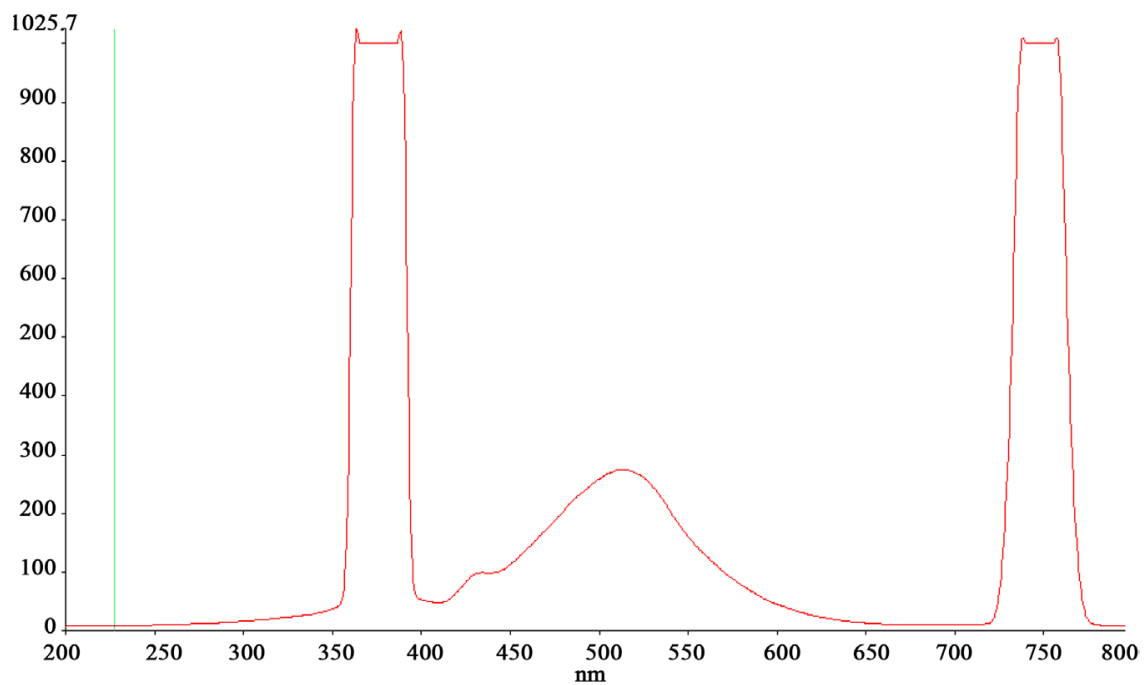

Figure 3. Spectrum of pure TCH.

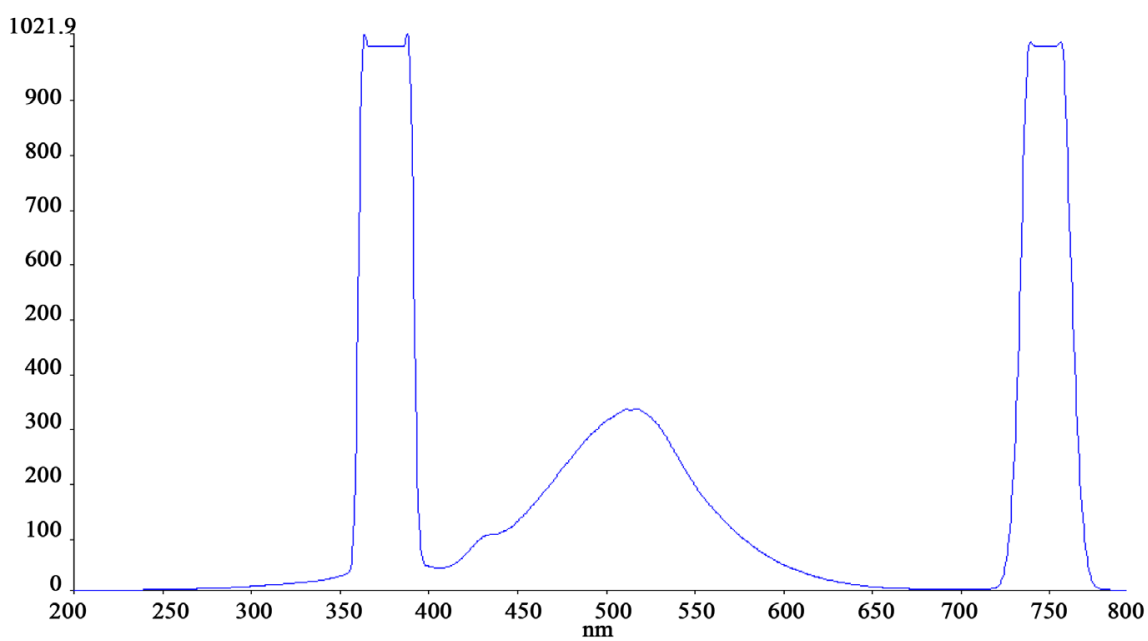

Figure 4. Spectrum of $\mathrm{TCH}$ in the matrix.

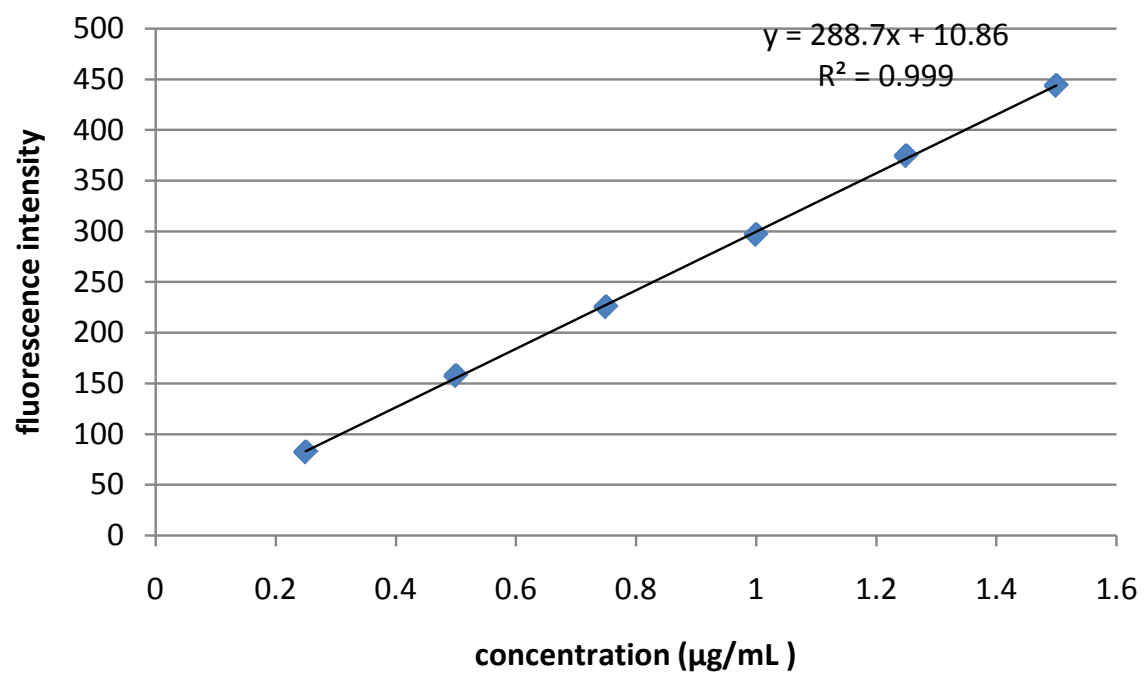

Figure 5. TCH Calibration Curve. 
The equation of regression way $y=289.11+10.448$ with a correlation coefficient $(\mathrm{R})$ of 0.9998 .

\subsection{Accuracy Profile}

The recovery data, precision and confidence interval are shown in Table 2 and Figure 6. For trueness, recoveries were between $99.88 \%$ and $101.10 \%$. For intraday and inter-day precision the RSD (relative standard deviation) between $1.57 \%$ and $2.88 \%$ were lower than $5 \%$.

\subsection{Application of the Validated Method for the Determination of TCH in Pharmaceutical Preparations}

To make the application of the method effective, it has been used for the direct determination of TCH in pharmaceutical preparations. Nine lots of THC capsules were separately selected for quantitative determination of THC. The THC content in samples collected from the market is determined qualitatively by the validated method and results are presented in Table 3.

\section{Discussion}

Although Tetracycline is soluble in aqueous solutions, water and methanol, it is far from stable in these solvents. Most often, it is transformed into Epitétracycline hydrochloride (ETC). This epimerization reaction is reversible. In the presence of divalent cations the reaction is not made [11].

Dissolved in water, no signal was found for TCH; on the other hand dissolved in water in the presence of $\mathrm{Mg}$ at a $\mathrm{pH}$ of 5.6, a signal was found at $380 \mathrm{~nm}$ of

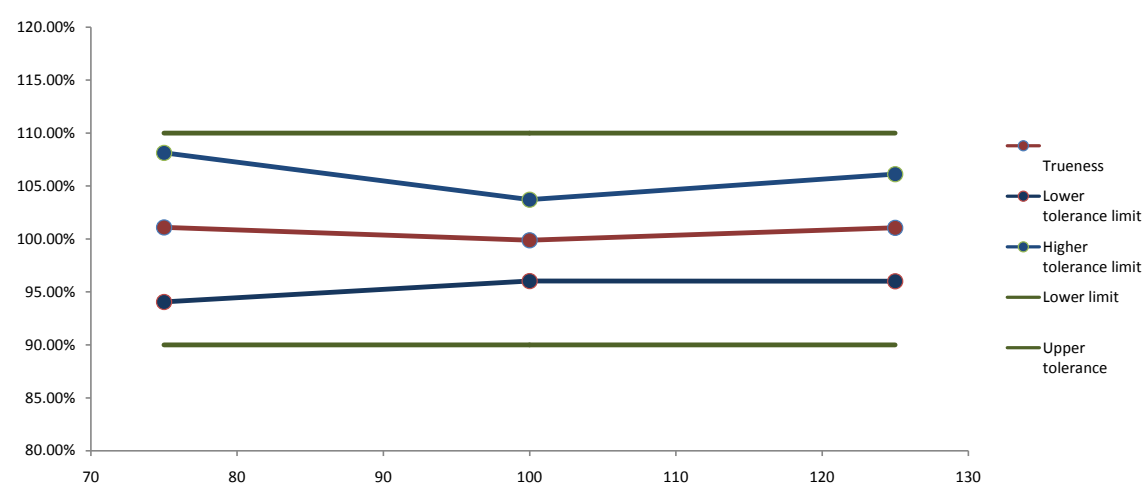

Figure 6. Diagram of the accuracy profile of the proposed method.

Table 2. Summary data for establishing the accuracy profile.

\begin{tabular}{|c|c|c|c|c|c|c|c|c|}
\hline concentration & Trueness & $\begin{array}{c}\text { Repeatability } \\
\text { RSD }\end{array}$ & $\begin{array}{c}\text { Intermediate } \\
\text { precision RSD }\end{array}$ & Tolerance & $\begin{array}{c}\text { Lower } \\
\text { tolerance limit }\end{array}$ & $\begin{array}{c}\text { Higher } \\
\text { tolerance limit }\end{array}$ & $\begin{array}{l}\text { Lower } \\
\text { limit }\end{array}$ & $\begin{array}{c}\text { Upper } \\
\text { tolerance }\end{array}$ \\
\hline $75 \%$ & $101.10 \%$ & $2.88 \%$ & $2.88 \%$ & $7.04 \%$ & $94.06 \%$ & $108.13 \%$ & $90 \%$ & $110 \%$ \\
\hline $100 \%$ & $99.88 \%$ & $1.57 \%$ & $1.57 \%$ & $3.84 \%$ & $96.04 \%$ & $103.72 \%$ & $90 \%$ & $110 \%$ \\
\hline $125 \%$ & $101.07 \%$ & $1.80 \%$ & $2.07 \%$ & $5.06 \%$ & $96.01 \%$ & $106.13 \%$ & $90 \%$ & $110 \%$ \\
\hline
\end{tabular}

$\mathrm{T}=2.45 ; \mathrm{ddl}=6 ;$ alpha risk $=0.05$. 
Table 3. Results of samples assay.

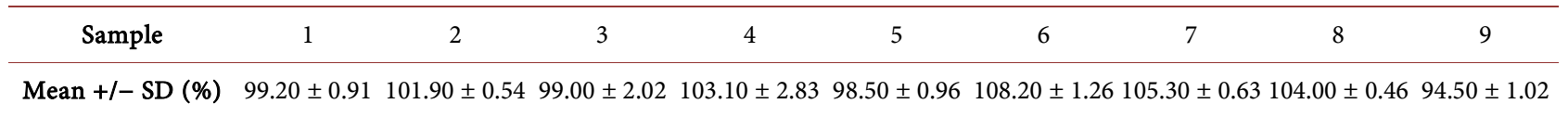

Mean: mean concentration; SD: standard deviation.

excitation and $520 \mathrm{~nm}$ of emission (Table 1). This coincided with the results found by Rodríguez et al. [12] using methanol as a diluent and other divalent cations selective for tetracycline [13] [14].

It turns out that $\mathrm{pH} 9$ is the one that gave the highest signal (Figure 2). THC is more fluorescent under these conditions, i.e. stable at $\mathrm{pH}>8$ [12].

Thus, for the analysis of TCH, distilled water (used as diluent), Borate at $\mathrm{pH} 9$ (buffer) and $\mathrm{MgSO}_{4} 0.75 \mathrm{M}$ (not only to boost fluorescence but also to keep the stability of the TCH ) are retained in this proposed method.

Linearity was established by the least squares regression method of the calibration curve. This standard curve was obtained in the range of 0.25 to 1.5 $\mu \mathrm{g} / \mathrm{mL}$. The correlation coefficient is greater than 0.9998 . The results show an excellent correlation between the fluorescent intensity and the concentration of the analyte. These values are in accordance with ICH specification [10].

The trueness recoveries were between $99.88 \%$ and $101.10 \%$. For intra-day and inter-day precision the relative standard deviation (RSD) between $1.57 \%$ and $2.88 \%$ were lower than $5 \%$.

These values below $5 \%$ indicate a good precision confirmed by the accuracy profile (Figure 6) which clearly shows the good quantitative method performance throughout the validation field [15].

The student test was used at $5 \%$ risk and at a degree of freedom of 6 , the found $\mathrm{t}$ is 2.45 , thus, the confidence interval found per level varies from 3.84 to $7.04 \%$. These values are in accordance with $\mathrm{ICH}$ specifiable accepted limit for tetracycline content varies from 90 to $125 \%$ for the American Pharmacopoeia [5] for our method the limit or interval of validity fixed is between $90 \%-110 \%$. With regard to the profile drawn (Figure 6), we note that the lower and upper bounds found vary from $94.06 \%$ to $108.13 \%$. This method is therefore valid in this concentration range.

Limits of detection and quantification are determined based on signal-tonoise ratios, comparing signals measured from samples of known concentrations of THC with the signal from the blank. Experimentally, the detection limit (LD) found is $0.0125 \mu \mathrm{g} / \mathrm{mL}$ and the limit of quantification (LOQ) is $0.0412 \mu \mathrm{g} / \mathrm{mL}$. This LOQ obtained is approximately 35 times lower than that $(1.739 \mu \mathrm{g} / \mathrm{mL}) \mathrm{re}$ ported for the spectrophotometric method [3]. It is close $(0.026 \mu \mathrm{g} / \mathrm{mL})$ to that reported for HPLC [6].

The content of our samples is quantitatively determined. The results found vary from $94.5 \%$ to $108.5 \%$. Margins of $(100 \pm 10) \%$ have been set as the acceptable limit for the method used. The results of the samples met the official acceptance criteria. 


\section{Conclusions}

The present work demonstrates that the method is fair, faithful, selective and sensitive. The linear response function was found for a range of concentrations ranging from 0.25 to $1.5 \mu \mathrm{g} / \mathrm{mL}$ with a correlation coefficient of 0.9998 .

Considering its low limit of detection and quantification, its sensitivity and selectivity, the method seems competitive with respect to titration and spectrophotometry which are reported as other analytical techniques. Although high performance liquid chromatography has a similar sensitivity, the method developed gives the advantage of being easy, fast, less expensive and avoids the tedious extraction procedure, the use of expensive and sometimes toxic organic solvents.

The validated spectrofluorimetry method was successfully applied in the direct determination of THC in 9 batches of pharmaceutical preparations.

It is therefore usable as a technique for routine analysis of tetracycline in pharmaceutical preparations.

\section{References}

[1] Drug Bank, Tetracycline (2016). http://www.drugbank.ca/drugs/DB00759

[2] Clarke (1986) Clarke's Isolation and Identification of Drugs in Pharmaceuticals. 2nd Edition, Pharmaceutical Press, London.

[3] Hadi, H. and Fadhil, G. (2014) Sensitive Spectrophotometric Determination of Tetracycline Hydrochloride in Dosage Forms Using Sodium Nitroprusside and Hydroxylamine Hydrochloride. Journal of Al-Nahrain University, 17, 53-58. https://doi.org/10.22401/JNUS.17.3.07

[4] Kowalski, P. (2008) Capillary Electrophoretic Method for the Simultaneous Determination of Tetracycline Residues in Fish Samples. Journal of Pharmaceutical and Biomedical Analysis, 47, 487-493.

[5] United States Pharmacopoeia (2016). http://www.pharmacopeia.cn/v29240/usp29nf24s0_m81820.html

[6] Hussien, E. (2014) HPLC Method Validation for Modernization of the Tetracycline Hydrochloride Capsule USP Monograph. Bulletin of Faculty of Pharmacy, 52, 239-244. https://doi.org/10.1016/j.bfopcu.2014.08.002

[7] Feinberg, M. (2010) Interpretation of the Accuracy Profile. Le Cahier des techniques de l'INRA, Special Volume, 45-60.

[8] Feinberg, M. (2006) Approche globale et harmonisée de la validation. Spectra Analyse No. 249.

[9] Recueil International des méthodes d'analyses (2016) Résolution OENO 7/2000. http://www.oiv.int/public/medias/2750/oiv-ma-as1-10fr.pdf

[10] ICH Validation of Analytical Procedures (1997) Text and Methodology. International Conference of Harmonization, 62, 27463-27467. www.ich.org/products/guidelines/quality/quality-single/article/validation-of-analyti cal-procedures-text-and-methodolo gy.html

[11] Florer, K. (1984) Analytical Profiles of Drug Substances. Academic Press, Cambridge, Vol. 13, 602-603, 613-616.

[12] Rodríguez, N., Ortiz, C., Herrero, A. and Sarabia, L. (2007) Performance Characte- 
ristics According to Commission Decision 2002/657/EC in the Fluorimetric Determination of Tetracycline in the Absence and in the Presence of Magnesium. Luminescence, 22, 518-526. https://doi.org/10.1002/bio.993

[13] Abdel-hady, M., Barary, H. and Mahgdub, H. (1985) Spectrofluorimetric Assay of Tetracycline and Anhydrotetracycline in Combination. Tafanto, 32, 1153-1155.

[14] Caswell, A. and Hutchison, J. (1971) Selectivity of Cation Chelation to Tetracyclines: Evidence for Special Conformation of Calcium Chelate. Biochemical and Biophysical Research Communications, 43, 625-630. https://doi.org/10.1016/0006-291X(71)90660-7

[15] ORA LABS (2014) Validation and Verification Guidance for Human Drug. Analytical Method, Appendix 1, 17-19. 